\title{
Penerapan Komunikasi Nirkabel LoRa pada Sistem Pencatat Kehadiran Portabel
}

\author{
Michael Paul Smart Simbolon ${ }^{1}$, Heru Wijanarko ${ }^{1 *}$, Fitriyanti Nakul ${ }^{1}$, dan Rahmi Mahdaliza ${ }^{1}$ \\ ${ }^{1}$ Politeknik Negeri Batam, Batam, Indonesia
}

*Email: wijanarko@polibatam.ac.id

\begin{abstract}
Abstrak-Long Rang Access (LoRa) merupakan bagian dari teknologi Low Power Wide Area Network (LPWAN) yang banyak digunakan karena memiliki karakteristik berdaya rendah dan dapat menjangkau area yang jauh secara nirkabel. Pada penelitian ini telah dilakukan penerapan komunikasi nirkael LoRa pada sistem pencatat kehadiran portabel yang dapat digunakan dosen dan dan karyawan serta mahasiswa dalam merekam presensi saat beraktifitas di luar ruangan. Setelah dilakukan instalasi dan konfigurasi, dilakukan pongujian baik di dalam maupun di luar area kampus Politeknik Negeri Batam. Terdapat sembilan titik lokasi pengujian di dalam area kampus dan delapan titik lokasi pengujian di luar area kampus. Dengan menggunakan LoRa yang bekerja pada frekuensi $915 \mathrm{MHz}$, set $\mathrm{SF}=7$ dan $\mathrm{BW}=125 \mathrm{KHz}$, didapatkan jangkauan terjauh hingga 456,01 meter. Keberhasilan penerimaan data dipengaruhi oleh jarak; banyak rintangan seperti beton, kaca, pepohonan dan gedung-gedung tinggi disekitar titi pengujian; frekuensi; dan bentuk antenna. Secara umum, komunikasi nirkabel LoRa dapat diterapkan pada sistem pencatat kehadiran portabel, namum masih terdapat ruang untuk pengembangan kedepannya terutama pada optimalisasi area jangkauan.
\end{abstract}

Kata Kunci: Nirkabel, LoRa, pencatat kehadiran, portabel

\section{Pendahuluan}

PENGAPLIKASIAN Internet of Things (IoT) membutuhkan lebih banyak teknologi yang dapat mendukung pengoperasian dengan daya rendah, yaitu end device berbiaya dan kompleksitas rendah yang dapat berkomunikasi jarak jauh secara nirkabel. Seperti dalam kebanyakan kasus, end device IoT adalah node sensor bertenaga baterai yang harus dirancang agar hemat dan memiliki life cycel time tinggi. Jangkauan komunikasi yang dibutuhkan mulai dari beberapa ratus meter hingga beberapa kilometer, agar end device dapat menjangkau area yang luas. Dengan pertimbangan beberapa karakteristik tersebut, solusi yang dapat digunakan adalah dengan tegnologi Low Power Wide Area Network (LPWAN).

Long Range Access (LoRA) merupakan salah satu teknologi komunikasi nirkabel untuk aplikasi Wireless Sensor Network (WSN) yang saat ini banyak digunakan. LoRa yang menjadi salah satu teknologi dari LPWAN memiliki frekuanesi kerja atau pita frekuensi $169 \mathrm{MHz}, 433 \mathrm{MHz}$, 868/915 MHz, dan 2.4 GHz. Dimana frekuensi tersebut dapat digunakan bebas atau tidak berlisensi [1]. Penelitan yang sudah pernah dilakukan dengan menggunakan LoRa diantaranya diaplikasikan pada: smart home [2], smart cities [3], dan juga diterapkan pada smart campus [4].

Politeknik Negeri Batam (Polibatam) memiliki kampus di kawasan Batam Center dimana terdapat beberapa gedung dan workshop yang letaknya terpisah. Selain gedung, terdapat fasilitas lainnya seperti lapangan voli, basket, futsal, taman dan area terbuka lainnya. Tidak jarang kegiatan perkuliahan atau aktifitas dosen dan karyawan Polibatam dilakukan di luar ruangan, seperti: praktikum lapangan untuk pemetaan kontur, kuliah olahraga atau kegiatan Jumat krida. Setiap dilakukan kegiatan Jumat krida karyawan dan dosen harus sidik jari kehadiran terlebih di gedung utama atau gedung Teaching Factory sebelum menuju lapangan olahraga. Aktifitas pencatatan kehadiran tersebut dirasa kurang efektif dan menghabiskan cukup banyak waktu. Untuk mengatasi masalah tersebut, dibutuhkan teknologi komunikasi nirkabel yang dapat menjangkau seluruh area kampus Polibatam. Penelitian sebelumnya [5], presensi karyawan dibuat menggunakan NodeMCU ESP8266 dimana menggunakan jaringan Wi-Fi. Jaringan Wi-Fi secara teknis dapat menjangkau hingga 46 meter (dalam ruangan) dan 92 meter (luar ruangan). Maka dari itu, penulis mencoba menerapkan komunikasi nirkabel LoRa yang dapat menjangkau area 5-15 kilometer pada sistem pecatat kehadiran yang mudah untuk dibawa dan dipindahkan (portabel). Selain pencatatan kehadiran yang bersifat portabel untuk dosen dan karyawan, diharapkan penelitian ini juga dapat dimanfaatkan untuk presensi kehadiran mahasiswa saat kuliah di luar ruangan.

\section{STUDI LITERATUR}

\section{A. LoRa dan LoRaWAN}

LoRa (bersamaan dengan lapisan atasnya - LoRaWAN) adalah bagian dari teknologi LPWAN pengiriman data yang menggunakan frekuensi radio sebagai media untuk pengiriman data. Sebagian besar unlicensed frequency (ISM) beroperasi 
pada frekuensi $169 \mathrm{MHz}, 433 \mathrm{MHz}, 868 \mathrm{Mhz}, 915 \mathrm{MHz}, 923$ Mhz, dan 2.4 Ghz. Untuk regional Indonesia, diizinkan menggunakan frekuensi $923 \mathrm{MHz}$. Dalam penelitian ini penulis menggunakan frekuensi $915 \mathrm{Mhz}$, sesuai dengan best tune frequency pada LoRaWAN gateway yang digunakan. Pada topology jaringan komunikasi LoRa, terdapat tiga komponen penting [6], yaitu:

1. End devices sebagai perangkat yang terhubung dengan sensor/akuator,

2. LoRa gateway, komponen yang berfungsi sebagai penghubung atau gerbang, dan

3. Netserver yang berfungi sebagai jaringan antarmuka ke semua jaringan mulai dari end node, gateway, database dan server.

LoRaWAN sebagai lapisan atas LoRa memiliki dua mekanisme penggabungan jaringan dan sistem keamanan dalam transfer data, yaitu metode Activation By Personalization (ABP) dan metode Over The Air Activation (OTAA). Pada penelitian ini penulis menggunakan prosedur $\mathrm{ABP}$, dimana proses end node mengirimkan request join ke gateway dan langsung mengirimkan data tanpa menerima join accepted. Sedangkan pada metode OTAA dimana end device mengirimkan request join dengan gateway dan harus menunggu join accepted dari gateway untuk melanjutkan kepada pengiriman data [7].

Dragino LoRa Shield adalah transceifer jarak jauh yang berbentuk shield Arduino berbasis open source. Dragino LoRa Shield ini memungkinkan pengiriman data dengan jarak yang jauh menggunakan frekuensi 433/868/915 MHz bergantung kepada konfigurasi pabrikan. Pada Dragino LoRa Shield ini menggunakan SX1276/SX1278 sebagai transceiver. LoRa shield ini memiliki spesifikasi, $168 \mathrm{~dB}$ maximum link budget, $+20 \mathrm{dBm}-100 \mathrm{~mW}$ constant $\mathrm{RF}$ output $\mathrm{Vs},+14 \mathrm{dBm}$ high efficiency PA. Bentuk fisik dari Dragino LoRa Shield dapat dilihat pada Gambar 1.

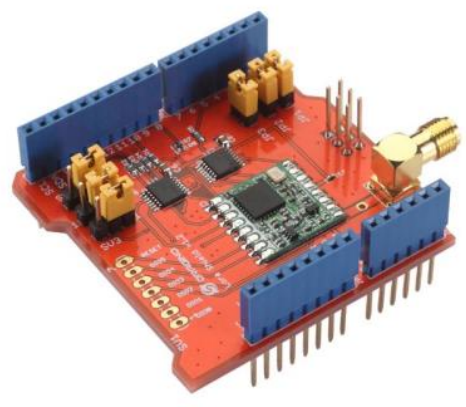

Gambar 1. Dragino LoRa shield [8]

LG02 adalah open souce dual channels LoRa gateway yang berfungsi sebagai gateway untuk menerima data dari board BL072Z. LG02 memiliki banyak pilihan koneksi internet, seperti: Wifi interface, Ethernet port dan USB host port. LG02, yang ditunjukkan pada Gambar 2, juga didesain untuk mengontrol SX1276/SX1278 LoRa Modul [9].

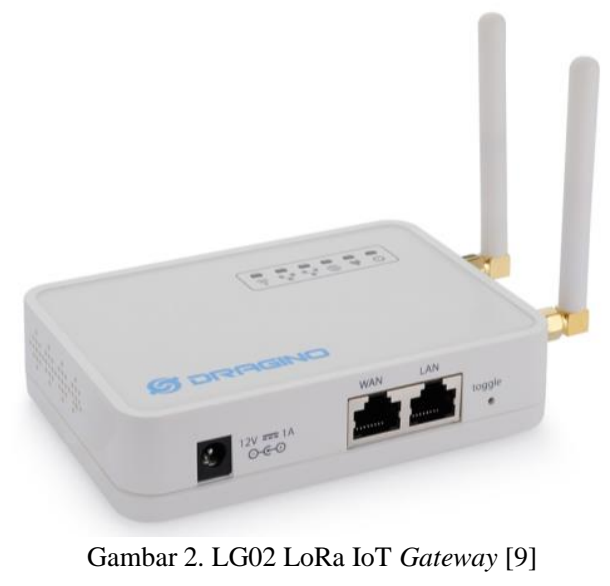

\section{B. Smart Card, RFID Reader, dan Fingerprint}

Smart card adalah kartu plastik yang terdapat IC yang ditanam di dalamnya. Oleh karena itu IC Card adalah istilah yang dipakai untuk smart card sendiri. Smart card bersifat portabel dan tamper-resistant. Tidak seperti kartu magnetic stripe yang biasa digunakan untuk kartu debit, smart card mampu menyimpan informasi dan melakukan pengolahan lokal pada data yang disimpan. Ukuran dari smard card adalah 85,6 $\mathrm{mm} \times 53,98 \mathrm{~mm} \times 0,76 \mathrm{~mm}$ atau dikenal juga dengan ID-1. Dalam perkembangan, smart card memiliki beberapa standar yang digunakan secara simultan dan diaplikasikan pada penggunaan yang berbeda yaitu format ID-1, ID-00, ID-000 (Mini SIM), Micro SIM, dan Nano SIM, seperti yang ditunjukkan pada Gambar 3.

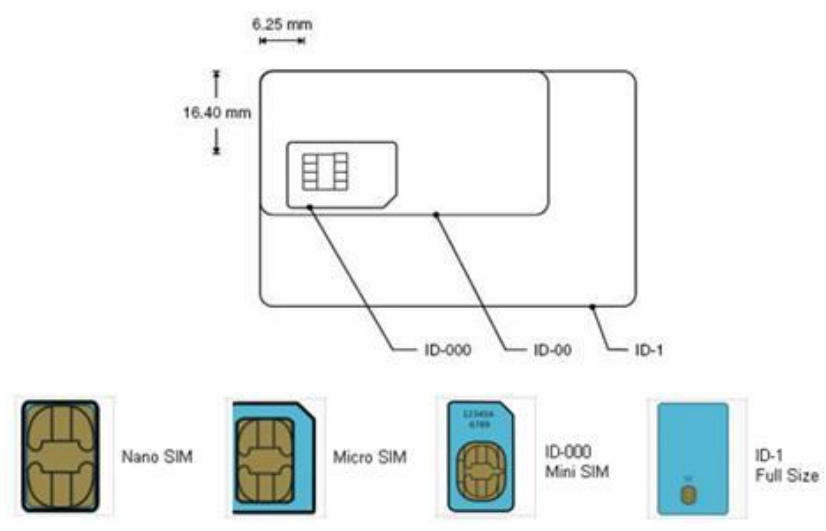

Gambar 3. Ukuran format kartu standar dari ID-1 hingga nano SIM

RC522 RFID reader merupakan alat yang digunakan sebagai pembaca smart card. Alat ini memancarkan frekuensi 13,56 $\mathrm{MHz}$ kemudian akan menerima pantulan dari smart card yang dapat memantulkan frekuensi yang sama. Gelombang radion yang dibaca, diterima bersamaan dengan data yang ada di chip smart card. Kemudian data yang terbaca di RFID reader akan dikirimkan ke PC menggunakan komunikasi Serial Peripheral Interface (SPI). Konfigurasi pin dari RC522 RFID reader dapat kita lihat pada Gambar 4. 


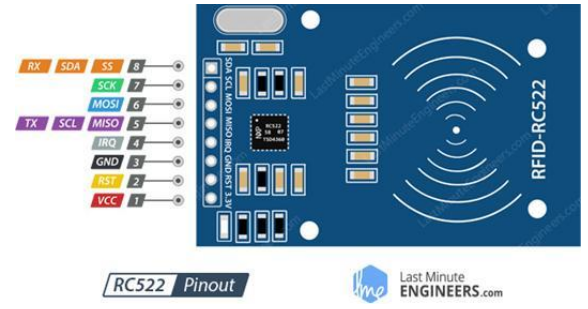

Gambar 4. Konfigurasi pin RFID-RC522 [10]

Fingerprint sensor adalah modul yang digunakan untuk mengenali jari yang sudah diverifikasi sebelumnya. Sensor fingerprint dapat mengenali sidik jari dengan menangkap gambar sidik jari lalu membandingkan dengan sidik jari yang sudah terdaftar. Bentuk fisik sensor fingerprint dapat dilihat pada Gambar 5.

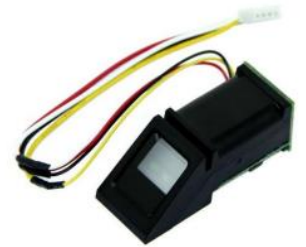

Gambar 5. Bentuk fisik sensor fingerprint [11]

\section{Catu Daya}

Salah satu komponen penting dalam ssebuah sistem adalah catu daya. Salah satu catu daya yang bersifat green dan mudah untuk dibawa serta dipindahkan adalah photovoltaic (PV). Komponen utama dari PV yang dapat menghasilkan energi listrik DC disebut juga panel surya. Panel surya (disajikan pada Gambar 6) terbuat dari bahan semikonduktor (umumnya silicon) yang apabila disinari oleh cahaya matahari dapat menghasilkan arus listrik.

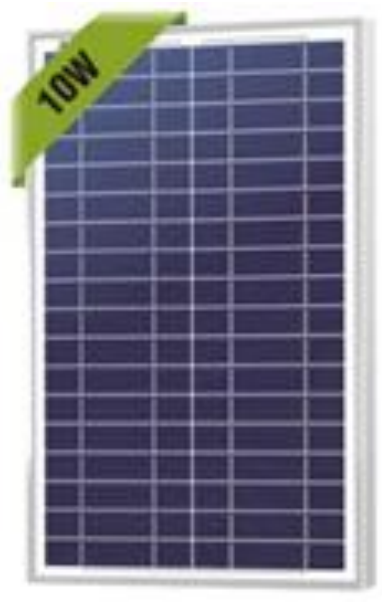

Gambar 6. Panel surya 10WP [12]

Charger controller adalah alat yang berfungsi untuk mengisi baterai dari panel surya. Alat ini juga dapat membantu keawetan dari baterai karena jika baterai sudah terisi penuh maka arus dari panel surya terputus. Jika daya pada baterai menurun, maka akan memulai pengisian baterai. Charger controller, yang ditampilkan pada gambar7, juga memiliki fungsi sebagai pengatur dalam menyediakan sumber tegangan atau daya yang akan dialirkan ke beban.

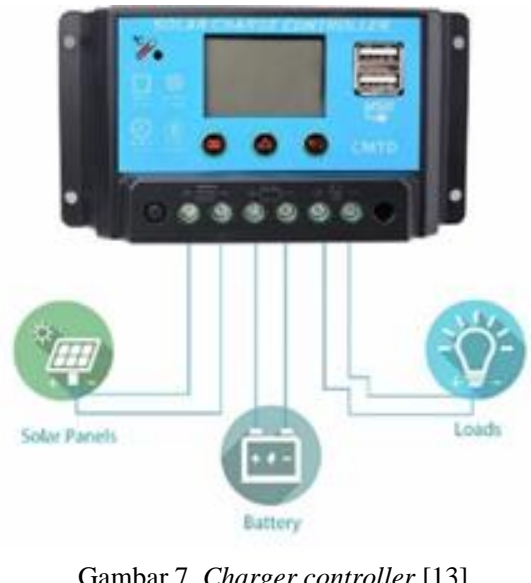

Baterai li-po adalah jenis baterai yang memiliki tingkat keawetan yang cukup lama. Baterai ini bersifat cair (liquid), menggunakan elektrolit polimer yang padat dan mampu menghantarkan daya lebih cepat dari baterai jenis lain. Baterai li-po ini juga disebut sebagai baterai yang ramah lingkungan. Dalam penelitian ini penulis menggunakan baterai li-po berkapasitas 1,5 Ah.

\section{METODE}

Pembuatan sistem pencatat kehadiran portabel yang menerapkan komunikasi nirkabel LoRa padanya dilakukan dalam beberapa tahapan, yang diawali dengan perancangan perangkat keras dan desain mekanik. Tahap selanjutnya adalah perancangan perangkat lunak, dan yang terakhir adalah pengujian. Proses pengujian dilakukan pada dua lokasi, yang pertama adalah di area kampus Polibatam dan yang kedua di luar area kampus.

\section{A. Perancangan Perangkat Keras}

Sistem pencatat kehadiran portabel pada penelitian ini didesain dengan perangkat keras yang dapat mendukung komunikasi nirkabel dan dicatu oleh baterai yang pengisian dayanya menggunakan tenaga surya. Gambar 8 menunjukkan topologi dari sistem pencatat kehadiran portabel.

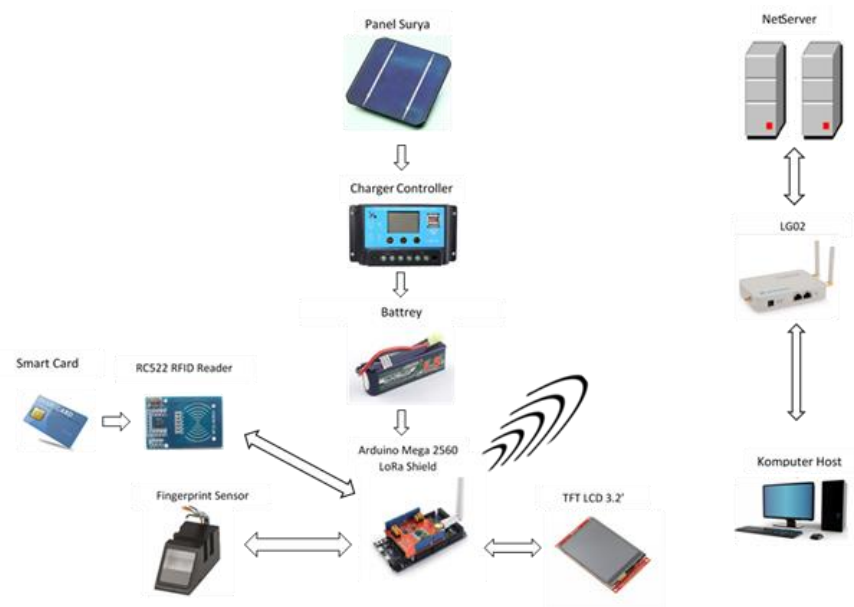

Gambar 8. Topologi sistem pencatat kehadiran portabel 
Pada topologi, dimulai dari sumber listrik panel surya kemudian masuk ke charger control yang berfungsi mengontrol keluaran tegangan. Kemudian daya masuk ke baterai, dan dialirkan ke masing-masing komponen. Pengiriman data awal dari RFID reader dan sensor fingerprint, dibaca oleh arduino. Data yang akan dikirim ditampilkan di TFT LCD dan dikirim ke LG02 LoRa gateway, selanjutnya data diteruskan ke komputer host dan server.

Sistem pencatat kehadiran portabel didukung dengan catu daya baterai dan memanfaatkan tenaga matahari sebagai sumbernya. Panel surya yang menerima energi matahari diteruskan ke solar charger controller yang berfungsi mengatur sistem pengisian daya dan keluaran tegangan yang mencatu arduino. Inputan 12 Volt disalurkan ke baterai sebagai penyimpan tenaga listrik. Kemudian keluaran 5 Volt disalurkan ke arduino mega dan arduino uno, lalu disalurkan ke fingerprint, TFT LCD, dan RFID reader. Blok diagram untuk rangkaian catu daya ditunjukkan pada Gambar 9.

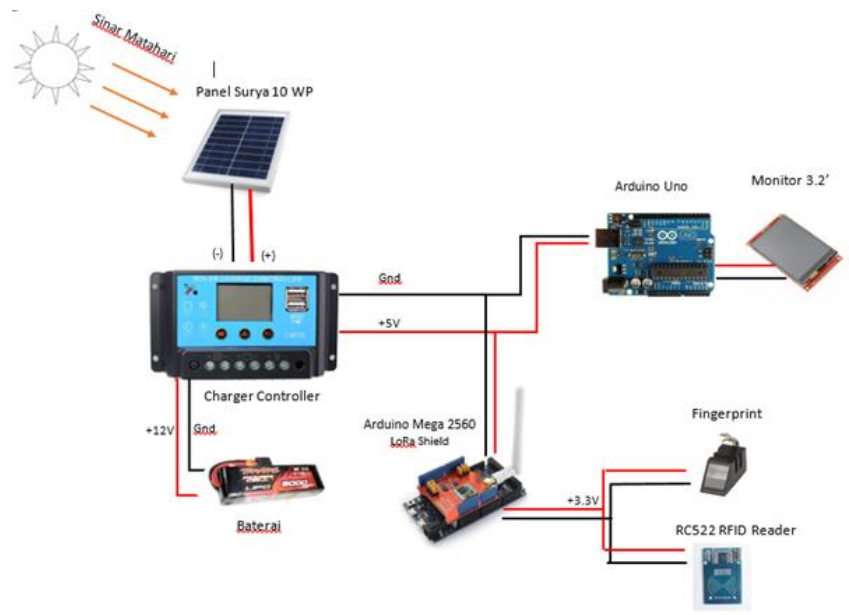

Gambar 9. Blok diagram rangkaian catu daya

Adapun desain mekanik disajikan pada Gambar 10. Panel surya berada pada bagian atas dari alat untuk menangkap sinar matahari tanpa halangan. Alat didesain agar dapat digunakan di luar ruangan dan portabel, dimana ditambahkan kaki atau tripod untuk mempermudah alat untuk dipindahkan. Kotak kontrol ditempatkan pada bagian tengah dan diatur dengan ketinggian yang proporsional agar dapat dijangkau oleh pengguna.

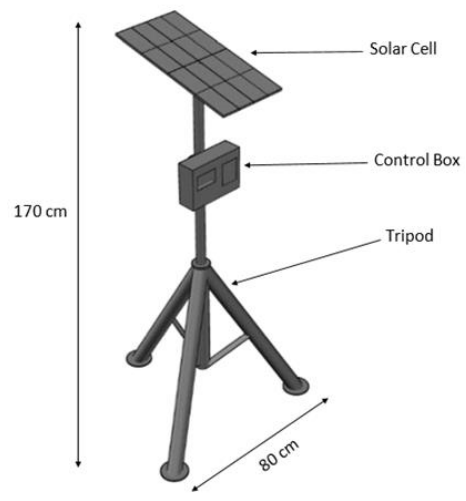

Gambar 10. Desain mekanik panel surya, kotak kontrol dan tripod

\section{B. Perancangan Perangkat Lunak}

Diagram alir perancangan perangkat lunak sistem dapat dilihat pada Gambar 11. Program awal adalah menampilkan selamat datang, menu pilihan user, mahasiswa atau dosen. Setelah itu, akan ditampilkan perintah untuk scan jari atau tap kartu. Jika identitas tidak dapat dikenali maka akan kembali ke point A. Sebaliknya jika identitas dikenali maka akan tampil notifikasi berhasil dan tampilan ucapan terima kasih pada LCD. Kemudian selanjutnya data identitas dikirimkan ke gateway.

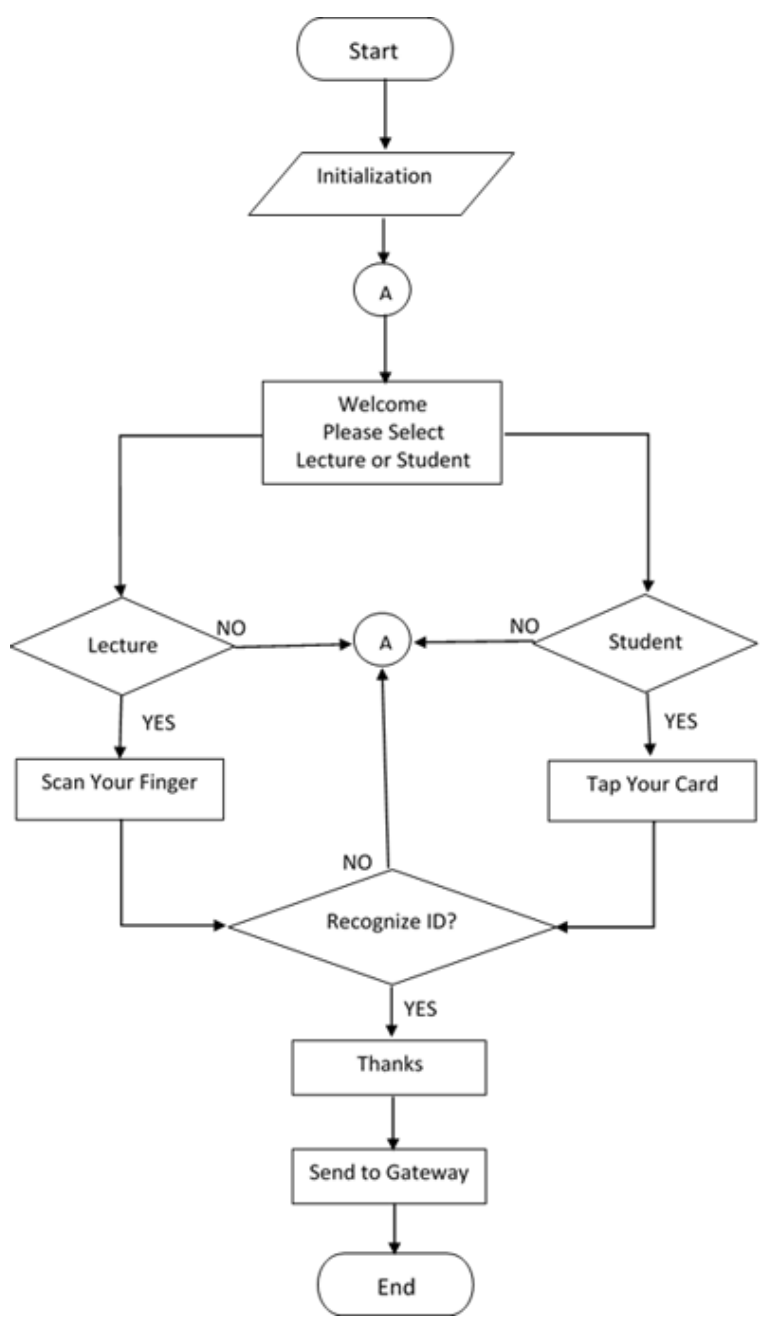

Gambar 11. Diagram alir desain perangkat lunak

\section{Pengujian}

Pengiriman data dilakukan pada dua lokasi pengujian. Pertama difokuskan di sekitar komplek kampus Polibatam, dan kedua dengan membawa alat ke luar area kampus. Dilakukan analisis jarak pengiriman terjauh beserta dengan rintangan yang ada, seperti gedung, pohon, papan iklan dan benda-benda yang berpotensi menghalangi pengiriman data. Pengujian alat dilakukan dengan cara memonitoring apakah terjadi pengiriman dan penerimaan data dari satu titik hingga ke titik terakhir yang ditentukan. Dalam pengujian, end node diletakkan pada titik-titik yang sudah ditentukan. Sedangkan LoRa gateway diletakkan di lantai 5 gedung utama Polibatam.

Gambar 12 menunjukkan peta lokasi dan titik pengujian di 
dalam area kampus Polibatam, dimana terdapat sembilan titik pengujian. Area dalam kampus Polibatam ditandai dengan zona atau garis biru, sedangkan titik pengujian diberi tanda merah.

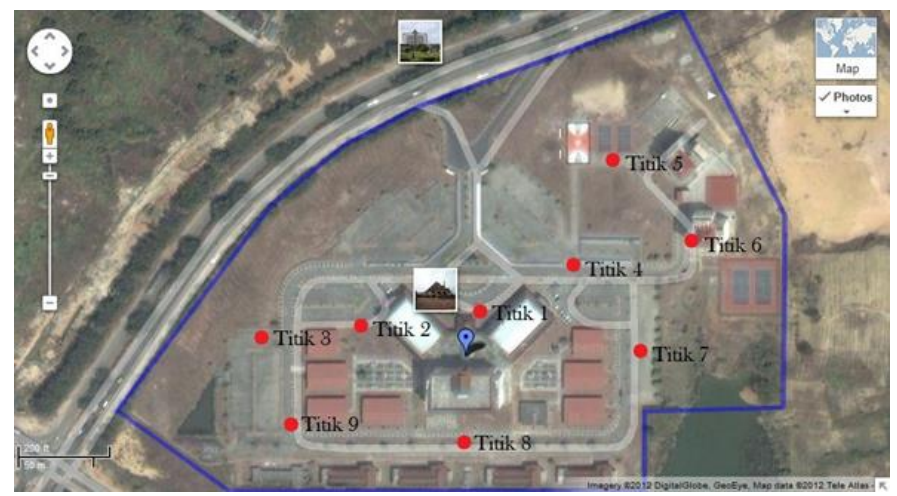

Gambar 12. Titik pengujian di area kampus Polibatam

Gambar 13 menunjukkan peta lokasi dan titik untuk pengujian di luar area kampus Polibatam. LoRa gateway ditempatkan pada gedung utama lantai 5 Polibatam yang ditandai dengan titik biru dan end node diposisikan pada titiktitik berwarna merah.

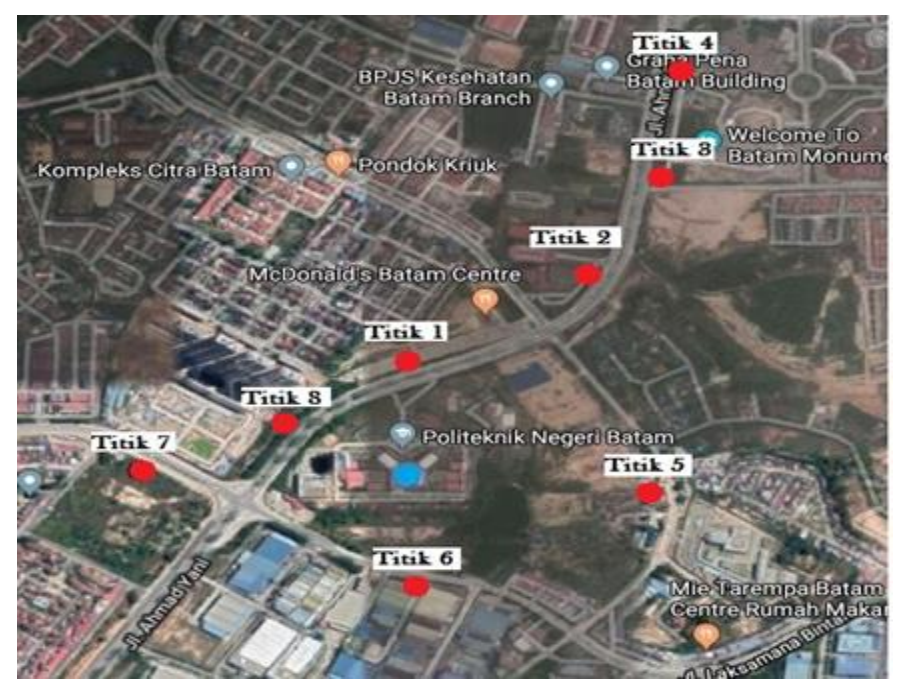

Gambar 13. Titik pengujian di luar area kampus Polibatam

\section{HASIL DAN PEMBAHASAN}

\section{A. Transmited Received Data di Area Kampus}

Data yang dibaca RFID reader dan fingerprint sensor menggunakan arduino dikirim ke gateway melalui LoRa shield dan diteruskan ke netserver. Data yang dikirim berupa ID mahasiswa sebanyak 8 bytes dan ID dosen sebanyak 6 bytes. Data yang diterima adalah ID yang ada pada payload. Setiap data yang terkirim akan terlihat downlink dan uplink pada netserver yang menandakan adanya kegiatan transmited receive data dari end node, gateway sampai di netserver.

Pengiriman data dilakukan di sembilan titik di area kampus Polibatam. Hal ini dilakukan guna mengetahui apakah pengiriman data dapat dilakukan secara maksimal dititik yang sudah ditentukan, dengan mencoba sampai percobaan sukses sebanyak minimal tiga kali.
Dapat dilihat pada tabel I terdapat lima titik percobaan yang berhasil mengirimkan dengan tingkat keberhasilan $100 \%$. Kegagalan pengiriman data paling banyak terjadi pada titik sembilan lokasi depan Hanggar. Dari tujuh kali percobaan berhasil tiga kali dan gagal sebanyak empat kali, hal ini dipengaruhi oleh jarak end node ke gateway sejauh 120,86 meter, dengan rintangan gedung utama, pohon, dan bengkel mesin yang menyebabkan daya serap sinyal yang berkurang dari end node ke gateway.

TABEL I

HASIL PERCoBAAN TRANSMITED RECEIVED DATA DI AREA KAMPUS

\begin{tabular}{|c|c|c|c|c|}
\hline Titik & $\begin{array}{c}\text { Jarak } \\
(\mathrm{m})\end{array}$ & $\begin{array}{c}\text { Tingkat } \\
\text { Keberhasilan }\end{array}$ & Lokasi & Rintangan \\
\hline 1 & 59,27 & $100 \%$ & $\begin{array}{l}\text { Depan tangga } \\
\text { lobby gedung } \\
\text { utama }\end{array}$ & $\begin{array}{l}\text { Beton dan kaca } \\
\text { gedung utama }\end{array}$ \\
\hline 2 & 78,90 & $100 \%$ & $\begin{array}{l}\text { Lapangan } \\
\text { parkir gedung } \\
\text { W7 }\end{array}$ & $\begin{array}{l}\text { Beton dan kaca } \\
\text { gedung utama, } \\
\text { pohon }\end{array}$ \\
\hline 3 & 145,48 & $60 \%$ & $\begin{array}{l}\text { Lobby gedung } \\
\text { Tower A }\end{array}$ & $\begin{array}{l}\text { Beton dan kaca } \\
\text { gedung utama, } \\
\text { pohon, workshop } \\
\text { W7 }\end{array}$ \\
\hline 4 & 106,11 & $100 \%$ & $\begin{array}{l}\text { Lapangan } \\
\text { parkir } \\
\text { mahasiswa }\end{array}$ & $\begin{array}{l}\text { Beton dan kaca } \\
\text { gedung utama }\end{array}$ \\
\hline 5 & 174,37 & $50 \%$ & Lapangan voli & $\begin{array}{l}\text { Beton dan kaca } \\
\text { gedung utama, } \\
\text { Auditorium A, } \\
\text { pohon }\end{array}$ \\
\hline 6 & 167,10 & $100 \%$ & $\begin{array}{l}\text { Lobby gedung } \\
\text { Teaching } \\
\text { Factory }\end{array}$ & $\begin{array}{l}\text { Beton dan kaca } \\
\text { gedung utama, } \\
\text { pohon }\end{array}$ \\
\hline 7 & 119,32 & $60 \%$ & $\begin{array}{l}\text { Depan } \\
\text { sekretariat } \\
\text { Mapala }\end{array}$ & $\begin{array}{l}\text { Beton dan kaca } \\
\text { gedung utama, } \\
\text { pohon, workshop } \\
\text { W1 dan W2 }\end{array}$ \\
\hline 8 & 53,29 & $100 \%$ & $\begin{array}{l}\text { Belakang } \\
\text { gedung utama } \\
\text { (Asrama } \\
\text { Mahasiswa) }\end{array}$ & $\begin{array}{l}\text { Beton dan kaca } \\
\text { gedung utama }\end{array}$ \\
\hline 9 & 120,85 & $42,86 \%$ & $\begin{array}{l}\text { Depan } \\
\text { Hanggar }\end{array}$ & $\begin{array}{l}\text { Beton dan kaca } \\
\text { gedung utama, } \\
\text { pohon, workshop } \\
\text { W5 dan W6 }\end{array}$ \\
\hline
\end{tabular}

Berdasarkan tabel I, terdapat 4 titik lokasi dimana tingkat keberhasilan tidak $100 \%$. Hal tersebut dikarenakan penghalang dari komunikasi LoRa tidak hanya beton dan kaca gedung utama tetapi juga terdapat pengahalang lain seperti workshop W7 untuk titik 3, workshop W1-W2 untuk titik 7, dan workshop W5-W6 untuk titik 9. Komunikasi dengan kondisi NLOS dan density tinggi tentunya akan mengurangi cakupan area dari sistem LoRa ini. 


\section{B. Transmited Received Data di luar Area Kampus}

Pada percobaan ini dengan memantau pengiriman data di luar area kampus Polibatam, guna mengetahui jarak terjauh dengan lokasi gateway berada di lantai 5 gedung utama. Pada tabel II dapat dilihat dari delapan titik lokasi percobaan, yang berhasil melakukan pengiriman data hanya dari tiga titik lokasi, dimana hal tersebut dipengaruhi oleh rintangan yang ada. Jarak terjauh trasnmited received data di luar area kampus adalah 456,01-meter dengan lokasi halte sekolah Global. Hal ini dapat dilihat karena rintangan yang ada hanya gedung utama dan pohon, sedangkan jika berdasarkan jarak kurang dari 400 meter, titik 8 lokasi Taman Kota juga tidak berhasil.

TABEL II

HASIL PERCobaAn TRANSMITED RECEIVED DATA DI LUAR AREA KAMPUS

\begin{tabular}{|c|c|c|c|c|}
\hline Titik & Lokasi & Jarak (m) & $\begin{array}{c}\text { Transmit } \\
\text { Receive } \\
\text { Data }\end{array}$ & Rintangan \\
\hline 1 & $\begin{array}{l}\text { Halte } \\
\text { Seberang } \\
\text { Kampus } \\
\text { Polibatam }\end{array}$ & 238,64 & Berhasil & $\begin{array}{l}\text { Beton dan kaca } \\
\text { gedung utama, pohon }\end{array}$ \\
\hline 2 & $\begin{array}{l}\text { Halte } \\
\text { Sekolah } \\
\text { Global }\end{array}$ & 456,01 & Berhasil & $\begin{array}{l}\text { Beton dan kaca } \\
\text { gedung utama, pohon }\end{array}$ \\
\hline 3 & $\begin{array}{l}\text { Halte } \\
\text { Masjid } \\
\text { Agung }\end{array}$ & 935,35 & $\begin{array}{l}\text { Tidak } \\
\text { Berhasil }\end{array}$ & $\begin{array}{l}\text { Beton dan kaca } \\
\text { gedung utama, pohon, } \\
\text { sekolah Global, } \\
\text { gedung Graha Pena, } \\
\text { papan iklan }\end{array}$ \\
\hline 4 & $\begin{array}{l}\text { Simpang } \\
\text { Welcome to } \\
\text { Batam } \\
\text { (WTB) }\end{array}$ & 735,32 & $\begin{array}{l}\text { Tidak } \\
\text { Berhasil }\end{array}$ & $\begin{array}{l}\text { Beton dan kaca } \\
\text { gedung utama, pohon, } \\
\text { gedung showroom, } \\
\text { papan iklan }\end{array}$ \\
\hline 5 & $\begin{array}{l}\text { GMIT } \\
\text { Batam } \\
\text { Center }\end{array}$ & 456,19 & $\begin{array}{l}\text { Tidak } \\
\text { Berhasil }\end{array}$ & $\begin{array}{l}\text { Beton dan kaca } \\
\text { gedung utama, pohon, } \\
\text { gedung GMIT }\end{array}$ \\
\hline 6 & $\begin{array}{l}\text { Sekolah } \\
\text { Basic }\end{array}$ & 218,14 & Berhasil & $\begin{array}{l}\text { Beton dan kaca } \\
\text { gedung utama, pohon }\end{array}$ \\
\hline 7 & $\begin{array}{l}\text { Depan pintu } \\
\text { masuk } \\
\text { Meisterstadt }\end{array}$ & 407,65 & $\begin{array}{l}\text { Tidak } \\
\text { Berhasil }\end{array}$ & $\begin{array}{l}\text { Beton dan kaca } \\
\text { gedung utama, pohon, } \\
\text { gedung Tower A } \\
\text { Polibatam, papan } \\
\text { iklan }\end{array}$ \\
\hline 8 & Taman Kota & 216,3 & $\begin{array}{l}\text { Tidak } \\
\text { Berhasil }\end{array}$ & $\begin{array}{l}\text { Beton dan kaca } \\
\text { gedung utama, pohon, } \\
\text { gedung Tower A } \\
\text { Polibatam }\end{array}$ \\
\hline
\end{tabular}

Hasil pengiriman data dari delapan titik lokasi di luar kampus, didapatkan tiga titik lokasi berhasil diterima oleh LoRa gateway. Dengan menggunakan Dragino LoRa Shield dengan frekuensi $915 \mathrm{MHz}$, terdapat beberapa faktor yang mempengaruhi. Pertama bentuk antena pada end node dan antenna LoRa gateway, kedua jarak end node dengan LoRa gateway, ketiga banyaknya penghalang seperti pohon, bangunan, dan penghalang lainnya, keempat faktor interferensi frekuensi $915 \mathrm{MHz}$ yang merupakan batas uplink dari GSM yang mempengaruhi interferensi penerimaan data.

\section{KESIMPULAN}

Dari hasil pengujian atau percobaan dapat disimpulkan bahwa komunikasi nirkabel menggunakan LoRa dapat diterapkan pada sistem pencatat kehadiran portabel. Keberhasilan proses transmited received data dipengaruhi oleh jarak, banyak rintangan, frekuensi dan bentuk antena. Jangkauan maksimal pengiriman data dapat dilakukan hingga kurang lebih 450-meter dengan letak LoRa indoor gateway di lantai 5 gedung utama Polibatam, dengan spesifikasi LoRa frekuensi kerja $915 \mathrm{MHz}$, set $\mathrm{SF}=7$ dan $\mathrm{BW}=125 \mathrm{KHz}$.

\section{REFERENSI}

[1] M. Centenaro, L. Vangelista, A. Zanella, and M. Zorzi, "Long-range communications in unlicensed bands: the rising stars in the IoT and smart city scenarios," IEEE Wireless Communications, vol. 23, no. 5, pp. 60-67, Oct. 2016, doi: 10.1109/MWC.2016.7721743.

[2] F. A. R. Mu'amar Wildan, E. A. Z. Hamidi, and T. Juhana, "The Design of Application for Smart Home Base on LoRa," in 2020 6th International Conference on Wireless and Telematics (ICWT), Sep. 2020, pp. 1-6. doi: 10.1109/ICWT50448.2020.9243648.

[3] K. Tzortzakis, K. Papafotis, and P. P. Sotiriadis, "Wireless self powered environmental monitoring system for smart cities based on LoRa," in 2017 Panhellenic Conference on Electronics and Telecommunications (PACET), Nov. 2017, pp. 1-4. doi: 10.1109/PACET.2017.8259970.

[4] S.-Y. Wang et al., "Performance of LoRa-Based IoT Applications on Campus," in 2017 IEEE 86th Vehicular Technology Conference (VTC-Fall), Sep. 2017, pp. 1-6. doi: 10.1109/VTCFall.2017.8288154.

[5] A. Kurniawan, "Pembuatan Sistem Presensi Karyawan Berbasis Mikrokontroler NodeMCU ESP8266 Terintegrasi Web di Qiblat Indonesia," Laporan Akhir, Program Studi Teknik Komputer, Sekolah Vokasi Institut Pertanian Bogor, Bogor, 2020.

[6] M. Diana, R. Nazir, and A. Rufiyanto, "Harvesting RF Ambient Energy dari End Device LoRa (Long Range Access)," JURNAL INFOTEL, vol. 9, no. 4, Art. no. 4, Nov. 2017, doi: 10.20895/infotel.v9i4.282.

[7] J. Haxhibeqiri, E. De Poorter, I. Moerman, and J. Hoebeke, "A Survey of LoRaWAN for IoT: From Technology to Application," Sensors, vol. 18, no. 11, Art. no. 11, Nov. 2018, doi: $10.3390 / \mathrm{s} 18113995$.

[8] "Arduino Shield featuring LoRa ${ }^{\circledR}$ technology." https://www.dragino.com/products/lora/item/102-lora-shield.html (accessed Jun. 22, 2021).

[9] "LG02 Dual Channels LoRa IoT Gateway." https://www.dragino.com/products/lora-lorawan-gateway/item/135$\lg 02$. html (accessed Jun. 22, 2021).

[10] "In-Depth: What is RFID? How It Works? Interface RC522 with Arduino," Last Minute Engineers, Jul. 30, 2018. https://lastminuteengineers.com/how-rfid-works-rc522-arduinotutorial/ (accessed Jun. 22, 2021).

[11] "Grove - Fingerprint Sensor - Seed Wiki." https://wiki.seeedstudio.com/Grove-Fingerprint_Sensor/ (accessed Jun. 22, 2021)

[12] "Panel Surya 10 WP Shinyoku Polycrystalline," panel surya jakarta, panel surya murah, Panel Surya, Harga Panel Surya, Panel Tenaga Surya, Harga Tenaga Surya, Jual Panel Surya, May 26, 2015. https://panelsuryajakarta.com/panel-surya-10-wp-shinyokupolycrystalline/ (accessed Jun. 22, 2021).

[13] "Sunix ${ }^{\circledR} 10 \mathrm{~A} 12 \mathrm{~V} / 24 \mathrm{~V}$ Solar Charge Regulator Intelligent Solar Charge Controller, Display Overload Protection Temperature Compensation: Amazon.co.uk: Lighting." https://www.amazon.co.uk/Intelligent-Controller-ProtectionTemperature-Compensation/dp/B01J5A61B2 (accessed Jun. 22, 2021). 